(2) CrossMark

Cite this: RSC Adv., 2016, 6, 44873

Received 22nd March 2016 Accepted 29th April 2016

DOI: 10.1039/c6ra07555j

www.rsc.org/advances

\section{"Clickable" thiacalix[4]arene derivatives bearing polymerizable 1,3-butadiyne fragments: synthesis and incorporation into polydiacetylene vesicles $\uparrow$}

\author{
Vladimir Burilov, ${ }^{* a}$ Alsu Valiyakhmetova, ${ }^{a}$ Diana Mironova, ${ }^{a}$ Roman Safiullin, ${ }^{c}$ \\ Marsil Kadirov, ${ }^{\text {bc }}$ Kamil Ivshin, ${ }^{a}$ Olga Kataeva, ${ }^{\text {ab }}$ Svetlana Solovieva ${ }^{\mathrm{ab}}$ and Igor Antipin ${ }^{\mathrm{ab}}$
}

p-tert-Butylthiacalix[4]arene derivatives in 1,3-alternate stereoisomeric form bearing polymerisable 1,3-butadiyne fragments on the one side and amino/carboxylic groups on another were synthesized using stepwise functionalisation. Calixarene 7 embedded in polydiacetylene nanoparticles showed a selective colorimetric response toward lanthanide ions.

Recently, polymeric materials that undergo spectral changes in response to external mechanical stimuli have gained much attention..$^{1,2}$ A conjugated polymer, polydiacetylene (PDA), has a special place among such materials. PDA can be prepared from various kinds of self-assembled diacetylene monomers by simple photo polymerization ${ }^{3}$ and can be used for colorimetric detection of ions, ${ }^{4}$ chemicals, ${ }^{5}$ biomolecules, ${ }^{6,7}$ bacteria ${ }^{8,9}$ and $\mathrm{pH}^{10}$ or temperature changes. ${ }^{11}$ The key mechanism of the PDA colorimetric response lies in distortion of the $\pi$-conjugated backbone by external stimuli and appears as rapid color (blueto-red) and fluorescence changes (none-to-red). ${ }^{12}$ Functional groups on the surface of PDA nanoparticles or bilayer play the key role in colorimetric detection of target substrates.

(Thia)calix[4]arene derivatives are well-known objects of supramolecular chemistry with unique properties: variety of stereoisomeric configurations, easy functionalization of both upper and lower rim and preorganization effect. ${ }^{13,14}$ Their ability to form host-guest complexes and to bind both organic molecules and metal ions is successfully used in extraction; recognition of different substrates and as components of molecular devices. ${ }^{15-17}$ Azide- or terminal alkyne functionalities can

${ }^{a}$ Kazan Federal University, 18 Kremlevskaya st, Kazan, 420008, Russian Federation. E-mail: ultrav@bk.ru; Fax: +7-843-238-79-01; Tel: +7-843-2337344

${ }^{b}$ A.E.Arbuzov Institute of Organic \& Physical Chemistry, 8 Arbuzov str., Kazan, 420088, Russian Federation

'Kazan National Research Technological University, 68 Karl Marx str., Kazan, 420015, Russian Federation

$\dagger$ Electronic supplementary information (ESI) available. CCDC 1463902. For ESI and crystallographic data in CIF or other electronic format see DOI: 10.1039/c6ra07555j essentially extend the synthetic potential of calixarene platform by using of the copper-catalyzed azide-alkyne cycloaddition (CuAAC). ${ }^{18-20}$

So, the combination of unique receptor properties of calixarene derivatives with PDA as a signaling unit is very challenging in creation of colorimetric sensors. Thus, charged calixarene receptors, non-covalently embedded within vesicles comprising phospholipids and the PDA were successfully used for the color fingerprinting of proteins. ${ }^{21}$ Nevertheless direct covalent bounding of calixarene with PDA signaling unit is at high interest but represented only in covalent incorporation of calixarenes with PDA matrix via ester-linkage,$^{22}$ which is not hydrolytically stable in acidic/base conditions or in the presence of carboxylic ester hydrolases. ${ }^{23}$ It is noteworthy that thiacalix[4] arenes scaffold adopting 1,3-alternate stereoisomeric form is in a great importance since selective stepwise functionalization of macrocycle lower rim allows to create two molecular domains with quite different properties located on the opposite sides from macrocycle plane (Scheme 1). One of them provides polymerisable 1,3-butadiynic fragments; on other the target

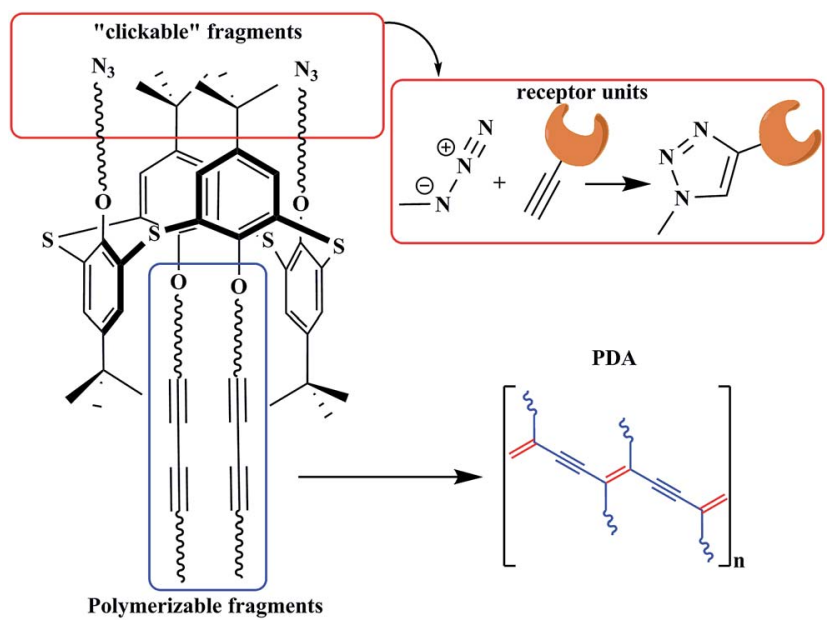

Scheme 1 
receptor fragments can be easily introduced and varied using click chemistry approach.

Herein we report a new synthetic strategy for the wide series of thiacalix[4]arene - based bifunctional receptors in 1,3-alternate stereoisomeric form bearing polymerizable 1,3-butadiyne fragments on the one side and azidopropyl fragments for the CuAAC reaction on another and the study of colorimetric response toward d-metal ions by receptors embedded in 10,12pentacosadiynoic acid (PCDA) vesicles.

Mitsunobu reaction is the most convenient method for the stepwise functionalization of thiacalix[4]arene lower rim by two different electrophilic reagents and leads to non-symmetrical tetra-substituted products in 1,3-alternate stereoisomeric form $^{\mathbf{2 4 , 2 5}}$ containing different functional groups on the opposite sides of the macrocycle (Scheme 2).

The stereoselective synthesis of polymerisable diazido precursor 3 was accomplished in a convergent fashion. The synthesis utilizes the 5-phenyl-2,4-pentadiyn-1-ol and 3-azido-1propanol as building blocks. Building blocks were synthesized by Cadiot-Chodkiewicz coupling reaction of propargyl alcohol with phenyl acetylene in the presence of $\mathrm{Cu}(\mathrm{I})$ chloride $^{26}$ and nucleophilic substitution of 3-bromo-1-propanol with sodium azide, correspondingly.

Obviously, there are two pathways (A or B on the Scheme 2) to the target precursor, that differ in the sequence of reactions. On the first step the substituents bearing terminal azide or 1,3butadiynoic fragments were introduced on the macrocycle. Reactions of parent thiacalix[4]arene with 5-phenyl-2,4pentadiyn-1-ol and 3-azido-1-propanol lead to the formation of expected distal disubstituted derivatives $\mathbf{1}$ and 2 in good yields. It is important to note that no Staudinger by-products (reaction of azides with triphenyl phosphine) were detected.

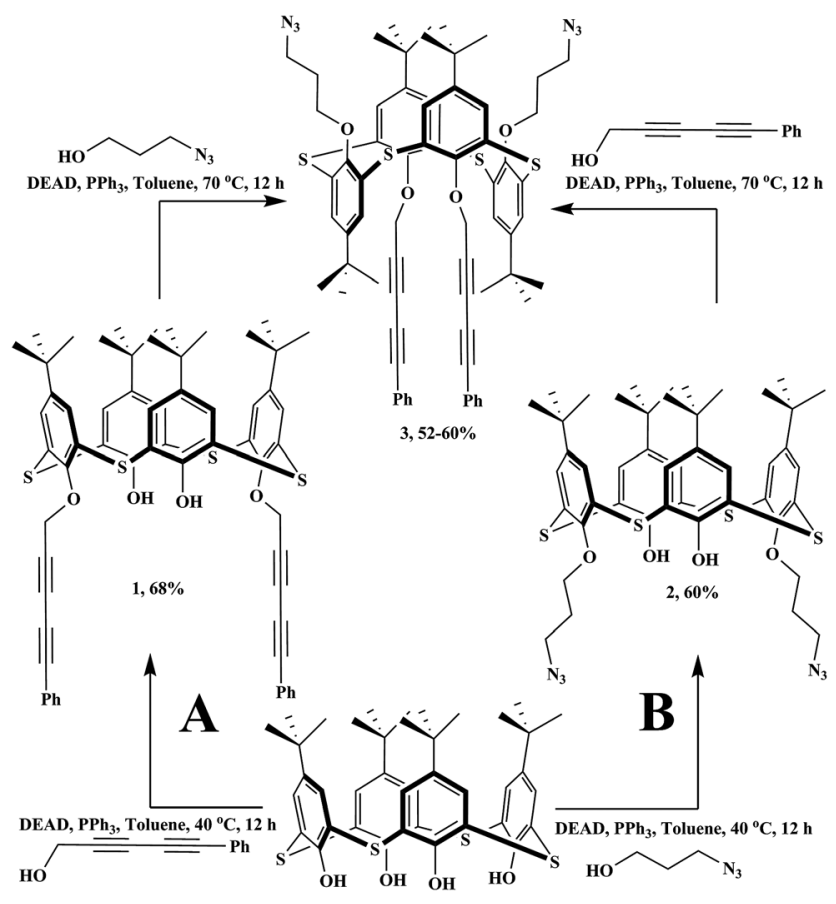

Scheme 2 Two pathways for synthesis of bifunctional thiacalixarene 3 .
So, azido-containing fragments can be directly attached to calixarene platform in Mitsunobu reaction conditions. Earlier azide-groups were only introduced on the thiacalix[4]arene platform by nucleophilic substitution of corresponding halogen derivatives. ${ }^{25}$

In this way thiacalixarene $\mathbf{3}$ was obtained by Mitsunobu reaction of 1 or 2 with 3-azido-1-propanol and 5-phenyl-2,4pentadiyn-1-ol, respectively, and there was no significant difference in the yields. So, the sequence of the reactions has no effect on the total yield of the final product.

Structures of compounds 1-3 were characterized by NMR, MALDI-TOF, IR and elemental analysis (see ESI $\dagger$ ). For compound 1 single crystals suitable for X-ray diffraction studies were obtained. According to the X-ray data O-substituted aromatic rings of the macrocycle are parallel to each other (Fig. 1). We found that it is general observation for distal disubstituted thiacalix[4] arene derivatives. ${ }^{27,28}$ Moreover, this is completely different from the behavior of disubstituted classical calix[4] arene $(\mathrm{C}[4] \mathrm{A})$ derivatives ${ }^{29}$ in which both $\mathrm{O}-\mathrm{R}$ fragments are fixed by intramolecular hydrogen bonding resulting in the rigid cup-shaped structure.

The reason of such behavior in disubstituted TC[4]A derivatives is $15 \%$ larger ring size of thiacalix[4]arene, ${ }^{30}$ that's why only one phenolic hydroxyl group can take part in hydrogen bonding (Fig. 1).

Stereoisomeric form of 3 was assigned as 1,3-altenate by the presence of high symmetric structure confirmed by ${ }^{1} \mathrm{H}$ NMR spectra and 2D NOESY NMR due to the existence of cross-peaks between signals of methylene protons of azidopropyl fragments $(\delta=4.04 ; 3.07 ; 1.63 \mathrm{ppm})$ and neighboring aromatic protons $(\delta$ $=7.35 \mathrm{ppm}$ ) as well as cross-peaks between signals of methylene protons of 5-phenylpenta-2,4-diyn fragments $(\delta=4.65$ ppm) and neighboring aromatic protons $(\delta=7.56 \mathrm{ppm})$ (Fig. 2).

Reaction of calixarene 3 with several alkynes was performed both in $\mathrm{Cu}(\mathrm{I})$ - catalyzed (for compounds 4,5 ) and uncatalyzed (for 7) conditions (Scheme 3). Reaction of $\mathbf{3}$ with acetylenedicarboxylic acid gave tetraacid 7 , reaction with $N$-propargyl phthalimide following by hydrazinolysis gave diamine 6 with good yields. No products of calixarene 3 self-cyclization were found. Low reactivity of disubstituted 1,3-butadiyne derivatives

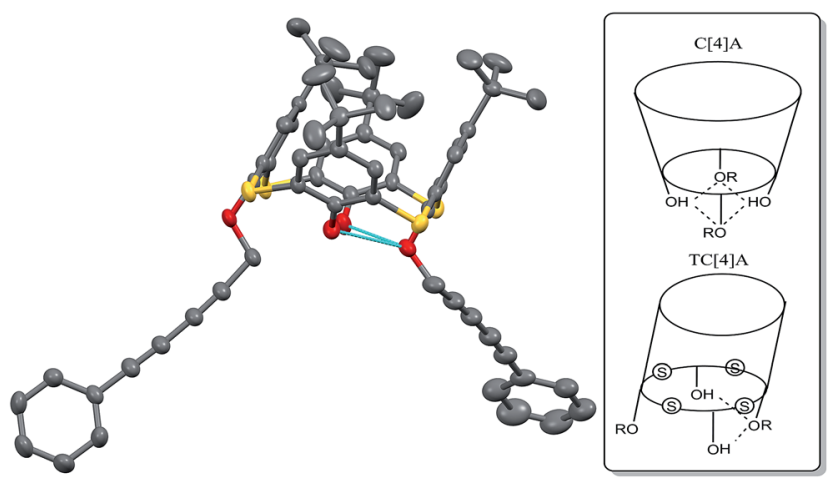

Fig. 1 Structure of 1 according to the $X$-ray data (hydrogen atoms are omitted for clarity) and intramolecular hydrogen bonding in C[4]A and TC[4]A derivatives. 


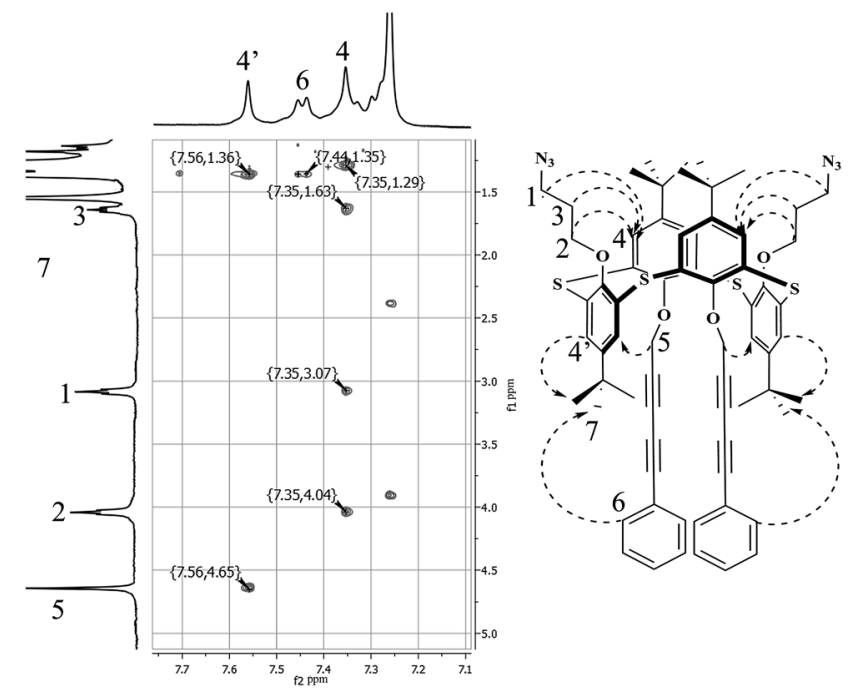

Fig. 2 2D NOESY NMR spectra of 3, $\mathrm{CDCl}_{3}$.

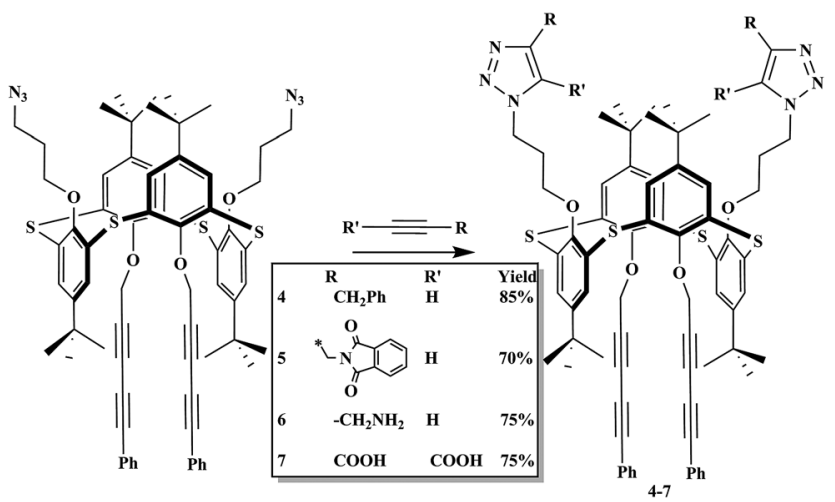

Scheme 3 Synthesis of triazoles 4-7, reaction conditions: Cul, NEt3, toluene, RT (for 4, 5); acetone, reflux (7) and $\mathrm{NH}_{2}-\mathrm{NH}_{2} \cdot \mathrm{H}_{2} \mathrm{O}$, EtOH, reflux (6).

in the cycloaddition reaction with azides ${ }^{31}$ is a reason of such result.

Calixarenes 6 and 7 were used in copolymerization with 10,12-pentacosadiynoic acid (PCDA), which is the most often used PDA source capable for vesicle formation. ${ }^{32}$ Despite low topochemical matching of diynoic fragments of calixarene and PCDA it is quite expected that calixarenes can form functional domains on the vesicle surface after polymerization. PCDAcalixarene vesicles were formed by well-known film hydration method. According to DLS data (Table 1) PCDA itself forms 200 $\mathrm{nm}$ sized vesicles, addition of anionic calixarene 7 at $\mathrm{pH} 7.4$ doesn't significantly affect to the size of vesicles, but addition of calixarene 6, which is mostly in cationic form at $\mathrm{pH} 7.4$, causes high aggregation of PCDA. Polymerization of PCDA-calixarene vesicles was performed under irradiation of $254 \mathrm{~nm}$ light in quarts $10 \mathrm{~mm}$ cuvettes was controlled by UV-visible spectroscopy. The maximum absorbance peak at $674 \mathrm{~nm}$, which corresponds to the "blue" form of PDA vesicles, appeared after 15 minutes of irradiation, and then polymer began to convert in "red" form. Thus 15 minutes is the optimal time for complete polymerization of PDA vesicles. The size of vesicles after polymerization decreases in all cases at about 30\% (Table 1). Zetapotential of polymerized vesicles is in full accordance with the nature of calixarene dopants. In the case of anionic calixarene 7 $\xi$-potential of negatively charged PDA vesicles is increased up to $-62 \mathrm{mV}$, whereas the presence of cationic calixarene 6 leads to its decreasing $(-37 \mathrm{mV})$.

According to the TEM data (Fig. 3) the shape of polymerized PDA vesicles has both spherical and tapered forms with size 150-200 nm, PDA doped with calixarene 6 has $200 \mathrm{~nm}$ single tapered particles and shapeless aggregates, and PDA doped with calixarene 7 has spherical shape particles with $100 \mathrm{~nm}$ in diameter. Non-spherical shape can be the main reason of high polydispersity indexes in DLS measurements.

Since PDA nanomaterial's with different functional groups on the surface were successfully used in detection of such ions as lead, silver, zinc, cadmium, manganese, silver, mercury, ${ }^{33-35}$ the study of the effect of calixarene doping on the colorimetric response of PDA vesicles in the presence of different metal ions was done. According to the obtained data (Fig. 4a) PDA-7 vesicles with $10 \%$ mol content of calixarene has a colorimetric response to lanthanide ions $\left(\mathrm{Gd}^{3+}, \mathrm{Tb}^{3+}\right.$ and $\mathrm{Dy}^{3+}$ were tested). Importantly that addition of other metal ions (except iron(II) and (III) ions that's colored due to the partial hydrolysis at $\mathrm{pH}$ 7.4) has no color effect on PDA-7 vesicles solution. Therefore selectivity upon lanthanide ions can be successfully used for lanthanide determination in the presence of other metal ions. The increase of calixarene content in PDA vesicles up to 20 mol\% (Fig. 4b) lead to significant increase of the colorimetric response toward lanthanide ions. Minimum detection limit is $0.01 \mathrm{mM}$ (see pic. 2 in ESI†).

It is noteworthy that PDA vesicles without calixarene additive (Fig. 4c) has no changes in absorption spectra upon addition of lanthanide ions. Moreover, the overall picture of colorimetric response for "pure" PDA vesicles is quiet differ - at the same concentrations they have response toward $\mathrm{Sr}(\mathrm{II}), \mathrm{Ca}$ (II) and $\mathrm{Pb}$ (II) (pic. 1, ESI $\dagger$ ). Thus, calixarene additive significantly changes

Table 1 DLS and $\xi$-potential data for PCDA-calixarene vesicle solution before and after UV polymerization ${ }^{a}$

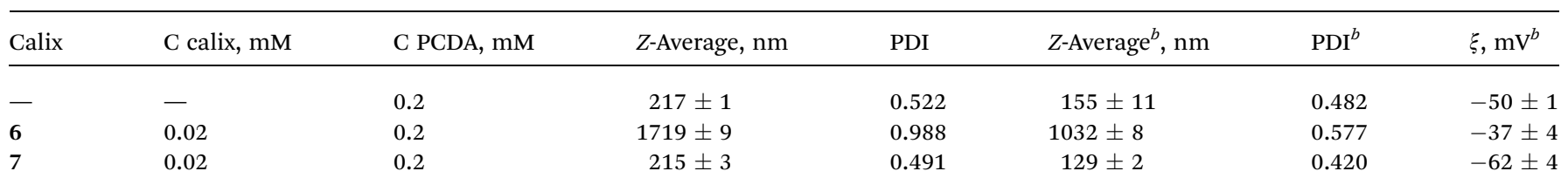

${ }^{a}$ Measurements were done at $10 \mathrm{mM}$ Tris buffer, $\mathrm{pH}=7.4 .{ }^{b}$ After polymerization. 


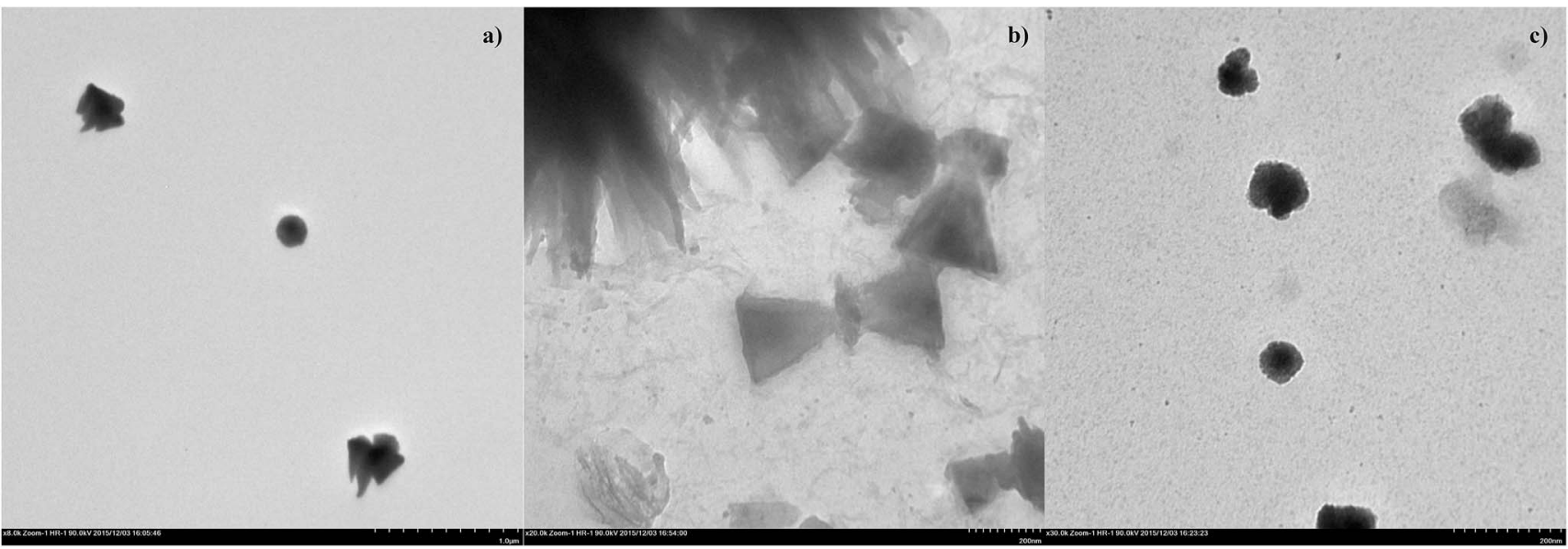

Fig. 3 TEM images of polymerized PDA vesicles (a), PDA-6 (b) and PDA-7 (c) vesicles, C(PCDA) $=0.2 \mathrm{mM}, C(\mathrm{calix})=0.02 \mathrm{mM}$.

a)

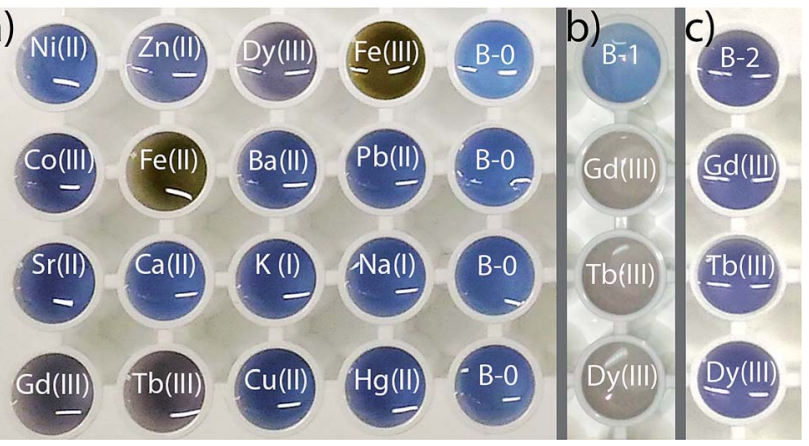

Fig. 4 Photograph of a portion of a 96-well plate containing: (a) $1 \mathrm{mM}$ of different metal ions chloride salts (except $\mathrm{Dy}^{3+}, \mathrm{Ba}^{2+}, \mathrm{Pd}^{2+}, \mathrm{Gd}^{3+}$, $\mathrm{Tb}^{3+}$ and $\mathrm{Hg}^{2+}$ were nitrates) and PDA-7 vesicles (blank B-0); (b) PDA-7 (blank B-1) or (c) PDA vesicles (blank B-2) with $\mathrm{Dy}^{3+}, \mathrm{Gd}^{3+}, \mathrm{Tb}^{3+}$ nitrates; $C(P C D A)=0.2 \mathrm{mM}, C($ calix $)=0.02 \mathrm{mM}$ (a) or $0.04 \mathrm{mM}(\mathrm{b})$ in $10 \mathrm{mM}$ Tris Buffer, $\mathrm{pH}=7.4$

affinity and selectivity of modified vesicles to metal ions. Recently $^{36}$ we have found that calixarene with the same functional dicarboxytriazolyl fragments can bind the $\mathrm{Tb}(\mathrm{III})$ ion due to the great affinity of carboxylate groups to lanthanide ions.

It is well known that calixarenes are allosteric systems: ${ }^{37}$ conformational changes of the molecule upon binding of analytes infavors or disfavors the subsequent binding (respectively, in the case of positive or negative allosteric effect). This effect is achieved through the flexibility of calixarene cavity at both cone and 1,3-alternate stereoisomeric forms. It often used for calixarene-based sensors containing receptor and indicator functions on the opposite sides of macrocycle plane. ${ }^{38,39}$ So, the selective colorimetric response upon addition of lanthanide ions can be attributed with the deformation of calixarene backbone caused by the strong complexation on the one side of calixarene platform and corresponding distortion of PDA $\pi$ conjugated backbone on other side of macrocycle.

Thus, suggested synthetic strategy for the thiacalix[4]arene based bifunctional receptors can be a good background for the design of the wide series of colorimetric sensors with an easily tunable selectivity.

\section{Conclusions}

For the first time a new synthetic strategy for the synthesis of wide series of thiacalix[4]arene - based bifunctional receptors in 1,3-alternate stereoisomeric form bearing polymerizable 1,3butadiyne fragments on the one side and azidopropyl fragments for the CuAAC reaction on another was demonstrated. Thiacalixarenes containing amino- and carboxylic groups were used in copolymerization with 10,12-pentacosadiynoic acid to give functional PDA nanoparticles. It was found that polymerized PDA vesicles with $20 \%$ mol content of calixarene 7 has significant colorimetric response toward lanthanide ions with the detection limit up to $0.01 \mathrm{mM}$. Great selectivity upon lanthanide ions can be a good basis for the analytical determination in the presence of other ions.

\section{Acknowledgements}

TEM images were carried out in the laboratory of "Transmission electron microscopy" of Kazan National Research Technological University. We thank the Russian Scientific Foundation for the financial support of this work (grant No. 14-13-01151).

\section{Notes and references}

1 M. M. Ali, D. K. Kang, K. Tsang, M. Fu, J. M. Karp and W. Zhao, Wiley Interdiscip. Rev.: Nanomed. Nanobiotechnol., 2012, 4, 547-561.

2 H. N. Kim, Z. Guo, W. Zhu, J. Yoon and H. Tian, Chem. Soc. Rev., 2011, 40, 79-93.

3 S. Okada, S. Peng, W. Spevak and D. Charych, Acc. Chem. Res., 1998, 31, 229-239.

4 S. Kolusheva, T. Shahal and R. Jelinek, J. Am. Chem. Soc., 2000, 122, 776-780.

5 J. Jaworski, K. Yokoyama, C. Zueger, W. J. Chung, S. W. Lee and A. Majumdar, Langmuir, 2011, 27, 3180-3187.

6 S. Kolusheva, L. Boyer and R. Jelinek, Mol. Reprod. Dev., 2000, 264, 225-227. 
7 C. H. Park, J. P. Kim, S. W. Lee, N. L. Jeon, P. J. Yoo and S. J. Sim, Adv. Funct. Mater., 2009, 19, 3703-3710.

8 Y. Scindia, L. Silbert, R. Volinsky, S. Kolusheva and R. Jelinek, Langmuir, 2007, 23, 4682-4687.

9 Z. Ma, J. Li, M. Liu, J. Cao, Z. Zou, J. Tu and L. Jiang, J. Am. Chem. Soc., 1998, 120, 12678-12679.

10 S. M. Ryu, I. Yoo, S. Song, B. Yoon and J. M. Kim, J. Am. Chem. Soc., 2009, 131, 3800-3801.

11 S. J. Kew and E. A. H. Hall, Anal. Chem., 2006, 78, 2231-2238.

12 M. A. Reppy and B. A. Pindzola, Chem. Commun., 2007, 43174338.

13 Z. Asfari, V. Bohmer, J. Harrowfield and J. Vicens, Calixarenes 2001, Kluver, Netherland, 2001.

14 R. Kumar, Y. O. Lee, V. Bhalla, M. Kumar and J. S. Kim, Chem. Soc. Rev., 2014, 43, 4824-4870.

15 M. Giuliani, I. Morbioli, F. Sansone and A. Casnati, Chem. Commun., 2015, 51, 14140-14159.

16 N. Morohashi, F. Narumi, N. Iki, T. Hattori and S. Miyano, Chem. Rev., 2006, 106, 5291-5316.

17 S. E. Solovieva, R. A. Safiullin, E. N. Kochetkov, N. B. Melnikova, M. K. Kadirov, E. V. Popova, I. S. Antipin and A. I. Konovalov, Langmuir, 2014, 30, 15153-15161.

18 V. V. Rostovtsev, L. G. Green, V. V. Fokin and K. B. Sharpless, Angew. Chem., Int. Ed., 2002, 41, 2596-2599.

19 N. V. Sokolova and V. G. Nenajdenko, RSC Adv., 2013, 3, 16212-16242.

20 V. A. Burilov, R. I. Nugmanov, E. V. Popova, I. R. Nabiullin, S. E. Solovieva, I. S. Antipin and A. I. Konovalov, Macroheterocycles, 2014, 7, 10-17.

21 S. Kolusheva, R. Zadmard, T. Schrader and R. Jelinek, J. Am. Chem. Soc., 2006, 128, 13592-13598.

22 D. L. Dermody, Y. Lee, T. Kim and R. M. Crooks, Langmuir, 1999, 15, 8435-8440.

23 F. Hasan, A. A. Shah and A. Hameed, Enzyme Microb. Technol., 2006, 39, 235-251.

24 I. Bitter and V. Csokai, Tetrahedron Lett., 2003, 44, 22612265.
25 V. A. Burilov, R. I. Nugmanov, R. R. Ibragimova, S. E. Solovieva and I. S. Antipin, Mendeleev Commun., 2015, 25, 177-179.

26 W. Chodkiewicz, Ann. Chim., 1957, 2, 819-869.

27 S. K. Latypov, S. V. Kharlamov, A. A. Muravev, A. A. Balandina, S. E. Solovieva, I. S. Antipin and A. I. Konovalov, J. Phys. Org. Chem., 2013, 26, 407-414.

28 S. E. Solovieva, E. V. Popova, A. O. Omran, A. T. Gubaidullin, S. V. Kharlamov, Sh. K. Latypov, I. S. Antipin and A. I. Konovalov, Russ. Chem. Bull., 2011, 60, 486-498.

29 L. C. Groenen, E. Steinwender, B. T. G. Lutz, J. H. van der Maas and D. N. Reinhoudt, J. Chem. Soc., Perkin Trans. 2, 1992, 1893-1898.

30 H. Akdas, L. Bringel, E. Graf, M. W. Hosseini, G. Mislin, J. Pansanel, A. D. Cian and J. Fischer, Tetrahedron Lett., 1998, 39, 2311-2314.

31 I. N. Domnin, L. A. Remizova, G. L. Starova and F. Rominger, Russ. J. Org. Chem., 2009, 45, 1678-1682.

32 S. Okada, S. Peng, W. Spevak and D. Charych, Acc. Chem. Res., 1998, 31, 229-239.

33 J. Guo, L. Yang, L. Zhu and D. Chen, Polymer, 2013, 54, 743749.

34 D. E. Wang, Y. Wang, C. Tian, L. Zhang, X. Han, Q. Tu, M. Yuan, S. Chen and J. Wang, J. Mater. Chem. A, 2015, 3, 21690-21698.

35 D. A. Jose and B. König, Org. Biomol. Chem., 2010, 8, 655-662.

36 V. A. Burilov, D. A. Mironova, R. R. Ibragimova, S. E. Solovieva, B. König and I. S. Antipin, RSC Adv., 2015, 5, 101177-101185.

37 L. Kovbasyuk and R. Krämer, Chem. Rev., 2004, 104, 31613187.

38 M. Kumar, A. Dhir and V. Bhalla, Tetrahedron, 2009, 65, $7510-7515$.

39 M. Kumar, R. Kumar and V. Bhalla, Tetrahedron Lett., 2010, 51, 5559-5562. 